\title{
Impedance Spectroscopy, Electrical Relaxation and Ac conductivity Studies of an Organic-Inorganic Hybrid Compound: $\mathrm{C}_{12} \mathrm{H}_{14} \mathrm{~N}_{2} \mathrm{CuCl}_{4}$
}

\author{
W. Wamani, R. Elwej, T. Mhiri and M. Belhouchet* \\ Laboratoire Physico-Chimie de l'Etat Solide, Université de Sfax, Département de Chimie, Faculté des \\ Sciences de Sfax, B. P. 1171, 3000 Sfax, Tunisia. \\ Laboratoire de l'Etat Solide, Université de Sfax, Département de physique, Faculté des sciences de Sfax, \\ B.P.1171, 3000 Sfax, Tunisia \\ *Corresponding author: belhouchet2002@yahoo.fr
}

\begin{abstract}
The $\mathrm{AC}$ conductivity of the compound, $\mathrm{C}_{12} \mathrm{H}_{14} \mathrm{~N}_{2} \mathrm{CuCl}_{4}$, in the temperature and frequency range from 373 to $423 \mathrm{~K}$ and $209 \mathrm{~Hz}-5 \mathrm{MHz}$, respectively, is reported. The differential scanning calorimetry and thermogravimetric analysis indicate the presence of a phase transition at $400 \mathrm{~K}$. The Z' and Z" vs. frequency plots are found to be well fit by using the equivalent circuit model. The circuits consist of a parallel combination of bulk resistance $R_{p}$ and constant phase element. Besides, the analysis of the experimental data based on the jump relaxation model shows that the translation motion of the charge carrier and reorientation hopping between the equivalent sites of the metal chloride anion and the cation groups are responsible for the observed AC conductivity in the temperature regions I (373-400 K) and II (400-423 K). The frequency dependence of the conductivity which follows the Arrhenius equation is interpreted in terms of Jonscher's law: $\sigma$ $(\omega)=\sigma_{d c}+A \omega^{s}$.
\end{abstract}

\section{Keywords:}

Organic-inorganic hybrid, Thermal behavior, Infrared spectroscopy, Nuclear magnetic resonance, Electrical impedance spectroscopy, Equivalent circuit, AC conductivity.

\section{Council for Innovative Research}

Peer Review Research Publishing System

\section{Journal: Journal of Advances in Chemistry}

Vol. 5, No. 3

editor@cirworld.com

www.cirworld.com, member.cirworld.com 


\section{INTRODUCTION}

Organic-inorganic hybrid materials have recently been synthesized in large quantities and their structures, performance and applications studied [1,2]. The design and synthesis of organic-inorganic hybrid perovskite materials have aroused great interest due to their unusual topological properties and potential applications in the fields of catalysis, biochemistry, magnetism and material science [3]. For the most part, organic amines were used as the organic component and divalent metal chlorides as the inorganic component [4]. In fact, organic molecules have specific properties of high fluorescence efficiency, large polarizability, plastic mechanical properties and structural diversity whereby inorganic materials may be characterized by a wide range of electronic properties, magnetic and dielectric transitions, substantial mechanical hardness and thermal stability [5]. Furthermore, optical, electrical, magnetic, and thermodynamic properties are useful in many applications and have attracted great attention [5]. For example, transition metal-layered perovskite-like hybrid compounds have been used as magnetic material owing to the inherent magnetic property of the transition metal [6].

Significant effort has been placed on both experimental and theoretical studies in this family of compounds in order to understand dynamical behavior. Most of this family members exhibit a structural phase transition with temperature $[7,8]$.

A variety of models have been proposed to explain AC conduction mechanisms [9, 10]. Since the complex impedance spectroscopy is a reliable method that can be used to study conduction processes [11, 12], its measurements are reported in this paper. The $A C$ conductivity and dielectric relaxation behavior of $\mathrm{C}_{12} \mathrm{H}_{14} \mathrm{~N}_{2} \mathrm{CuCl}_{4}$ single crystal have also been studied as a function of temperature and frequency.

\section{EXPERIMENTAL}

\subsection{Materials and measurements}

All reagents were purchased and used without further purification. Concerning the differential scanning calorimetry (DSC) measurements, they were carried out on heating sample $(6 \mathrm{mg})$ from $25-200^{\circ} \mathrm{C}$ on a Pyris 1 instrument at a heating rate of $5^{\circ} \mathrm{C} / \mathrm{min}$. As for the thermogravimetric analysis, it was obtained with a TGA 92 SETARAM analyzer. The powdered sample $\left(10 \mathrm{mg}\right.$ ) was heated from room temperature up to $300{ }^{\circ} \mathrm{C}$ at a rate of $5^{\circ} \mathrm{C} / \mathrm{min}$.

Infrared spectroscopy from 400-4000 $\mathrm{cm}^{-1}$ was performed with a FT-IR 2000 Perkin-Elmer spectrophotometer model. The pellet was prepared by mixing $15 \mathrm{mg}$ of powdered sample with $300 \mathrm{mg} \mathrm{of} \mathrm{KBr}$ (dried at $110^{\circ} \mathrm{C}$ ) and compressing the mixture into a disk.

${ }^{13} \mathrm{C}-\mathrm{NMR}$ was performed at room temperature on a Bruker DSX-300 spectrometer operating at $75.48 \mathrm{MHz}$. The powdered sample was packed in a 4-mm-diameter rotor and allowed to rotate at speeds reaching $10 \mathrm{kHz}$ in a Doty MAS probe-head. The spectrum was acquired by the use of cross-polarization for protons with $5 \mathrm{~ms}$ contact time. All chemical shifts are given according to tetramethylsilane.

The electrical measurements were performed using a two-electrode configuration on a polycristalline sample. The used pellets, whose discs were coated with $\mathrm{Ag}$ paste to ensure good electrical contact, were $8 \mathrm{~mm}$ in diameter and 1.2 $\mathrm{mm}$ in thickness. After the $\mathrm{Ag}$ coating and before measurements, the samples were first heated at $100{ }^{\circ} \mathrm{C}$ for 12 hours under vacuum. Electrical impedances were measured in the frequency range of $209 \mathrm{~Hz}-5 \mathrm{MHz}$ with a TEGAM 3550 ALF automatic bridge monitored by a microcomputer. Measurements were conducted from $373-423 \mathrm{~K}$.

\subsection{Chemical preparation}

The synthesis of $\mathrm{C}_{12} \mathrm{H}_{14} \mathrm{~N}_{2} \mathrm{CuCl}_{4}$ was performed from precursors benzedine (98\%), cooper oxide (99.99\%) and $\mathrm{HC}$ (36\%). The single crystals of $\mathrm{C}_{12} \mathrm{H}_{14} \mathrm{~N}_{2} \mathrm{CuCl}_{4}$ were prepared by dissolving cooper oxide $(0.12 \mathrm{~g}, 1.5 \mathrm{mmol})$ in dilute hydrochloric acid and 1,4-biphenylenediamine $(0.27 \mathrm{~g}, 1.5 \mathrm{mmol})$ in $10 \mathrm{ml}$ distilled water/ethanol $(5 \mathrm{ml}$ water/5 ml ethanol). The two solutions were then combined slowly in a beaker and allowed to evaporate at room temperature. After several days, yellow crystals were deposited.

\section{RESULTS AND DISCUSSIONS}

\subsection{Structure description}

The title compound is crystallized with $P 2_{1} / \mathrm{c}$ space group and the parameters are given as: $\mathrm{a}=14.3774(7), \mathrm{b}=$ 7.3472 (4), $c=7.1669$ (3), $\alpha=96.589(3)^{\circ}$, with $Z=2$ and $R 1=0.037$ [13]. Each copper atom lies at the center of a copper chloride octahedron, deformed due to the Jahn-Teller effect [14]. These octahedrons are polymerized in sheets. The structure consists of perovskite $\left[\mathrm{CuCl}_{4}^{2-}\right]_{n}$ layers sheathed by $\left[\mathrm{NH}_{3}\left(\mathrm{C}_{6} \mathrm{H}_{4}\right)_{2} \mathrm{NH}_{3}\right]^{2+}$ moieties. The inorganic framework, consisting of corner-shared tetragonally elongated octahedral $\mathrm{CuCl}_{6}$, shows the prototypic layer structure of the $\mathrm{NH}_{3}-\mathrm{R}-$ $\mathrm{NH}_{3} \mathrm{MX}_{4}$ perovskite salts. The shortest $\mathrm{Cu}$ - $\mathrm{Cl}$ bond in the coordination sphere is about $2.2791 \AA$ while the longer semicoordinate distance is $2.888 \AA$. As is always observed in the halocuprate perovskites, the semi-coordinate bonds are arranged in an antiferro distortive fashion and lie nearly in the plane of the perovskite sheets. Hence the corner sharing linkages involve one short and one long $\mathrm{Cu}-\mathrm{Cl}$ bonds. The bridging $\mathrm{Cu}-\mathrm{Cl}-\mathrm{Cu}$ angles are nonlinear, with values of $163.9^{\circ}$, yielding a corrugated sheet structure, as seen in Fig. 1. The sheathing of the perovskites layers by the $\left[\mathrm{NH}_{3}\left(\mathrm{C}_{6} \mathrm{H}_{4}\right)_{2} \mathrm{NH}_{3}\right]^{2+}$ moieties is stabilized via the hydrogen bonding of the $-\mathrm{NH}_{3}$ groups to the chloride ions in the inorganic framework. The $\mathrm{N}-$ $\mathrm{Cl}$ distances range from 3.223 to $3.269 \AA$ while the $\mathrm{N}-\mathrm{H}$...Cl angles are in the range of $154-168^{\circ}$. The main interest of this 
paper is the study of the thermal behavior and $\mathrm{AC}$ conductivity with the dielectric relaxation of the $\mathrm{NH}_{3}\left(\mathrm{C}_{6} \mathrm{H}_{4}\right)_{2} \mathrm{NH}_{3} \mathrm{CuCl}_{4}$ compound at various temperatures.

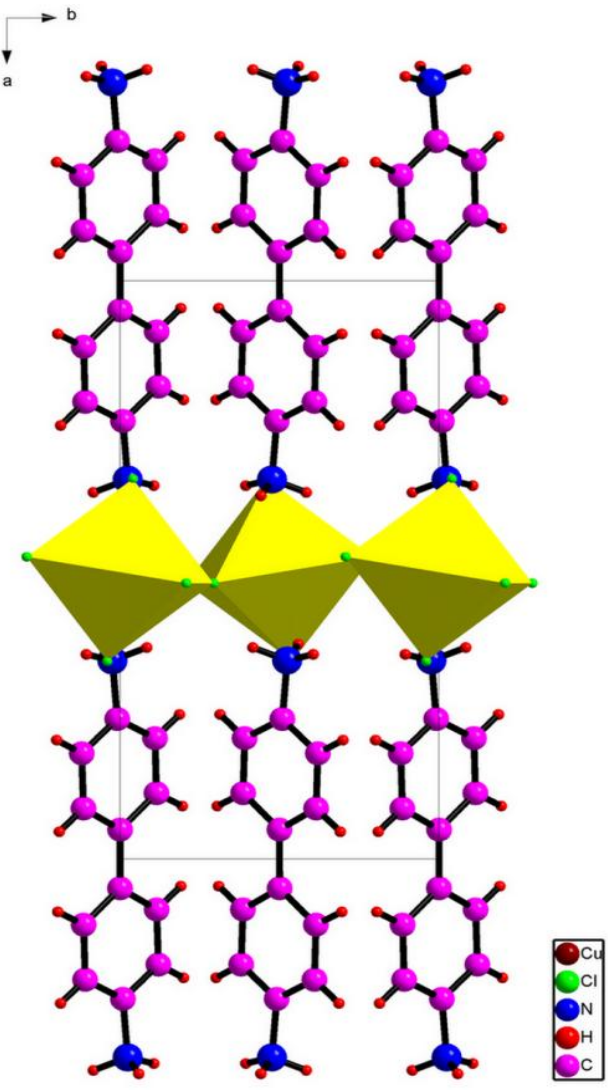

Fig 1: View down the $c$ axis of the structure of $\mathrm{C}_{12} \mathrm{H}_{14} \mathrm{~N}_{2} \mathrm{CuCl}_{4}$, showing alternating organic inorganic layers

\subsection{Thermal analysis}

The TGA curve shows a very important weight loss in the temperature range from $200^{\circ} \mathrm{C}$ to $300^{\circ} \mathrm{C}$ (Fig. 2), which corresponds to the compound decomposition. The DSC thermogram (Fig. 3) shows a single endothermic peak located at $\mathrm{T}=126^{\circ} \mathrm{C}$ without weight loss in the TGA curve characterizing the presence of a phase transition. DSC studies on the perovskite were undertaken demonstrating structural transitions below the melting/decomposition point [15, 16]. These transitions were explained by the delocalization of electrons moving in the aromatic ring

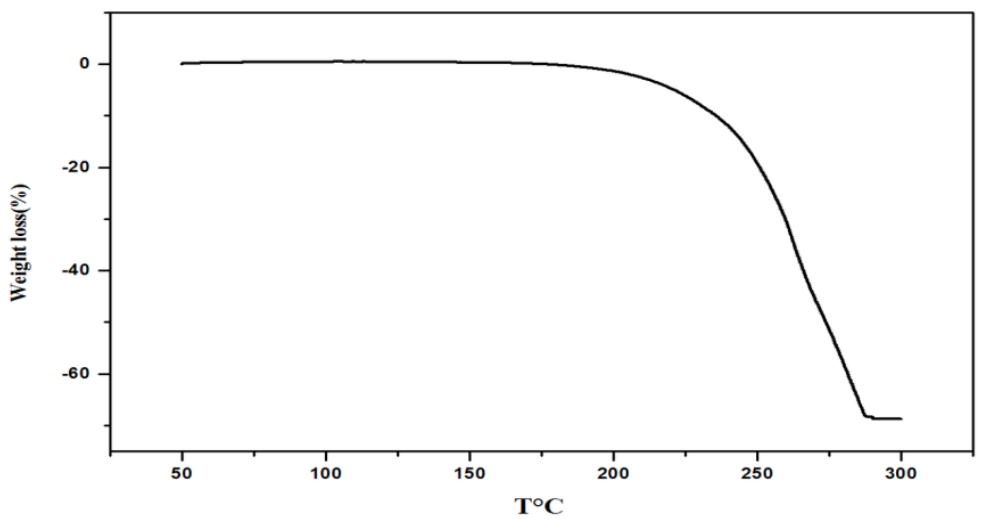

Fig 2: Thermogravimetric analysis of $\mathrm{C}_{12} \mathrm{H}_{14} \mathrm{~N}_{2} \mathrm{CuCl}_{4}$ 


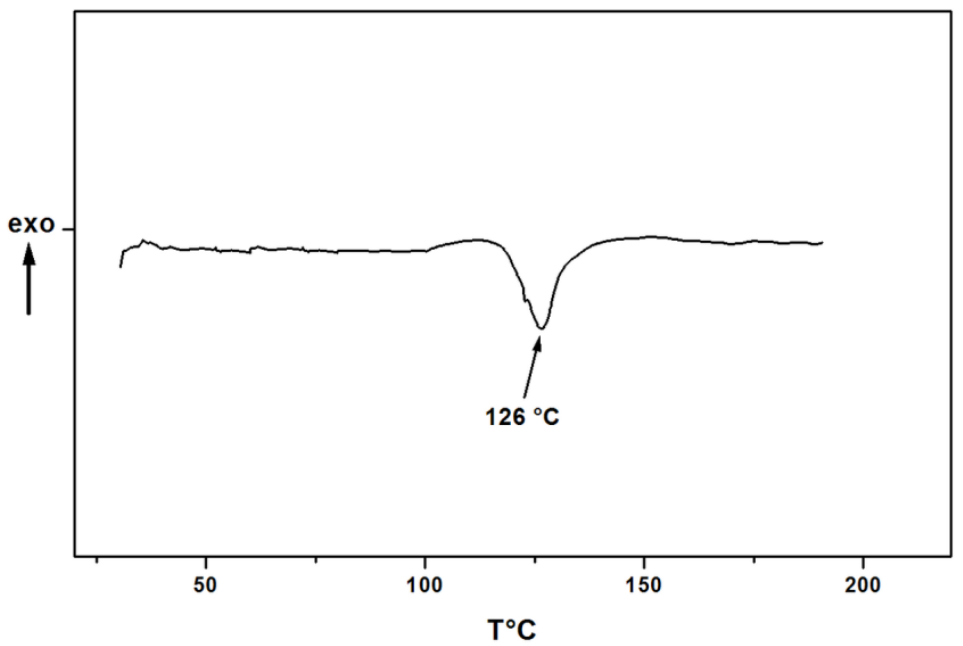

Fig 3: Differential scanning calorimetric analysis of $\mathrm{C}_{12} \mathrm{H}_{14} \mathrm{~N}_{2} \mathrm{CuCl}_{4}$

\subsection{FT-IR Spectra}

The assignment of the internal modes of the organic cation, observed in the infrared spectrum (Fig. 4), is based on the comparison with the well-documented spectra of the homologous compounds $[17,18]$. The broad absorption bands in the $2800-3400 \mathrm{~cm}^{-1}$ range are due to $\mathrm{NH}_{3}$ and $\mathrm{C}-\mathrm{H}$ stretching modes. Frequencies in the range of $1000-1500 \mathrm{~cm}^{-1}$ are assigned to the $\mathrm{C}-\mathrm{H}$ bending, $\mathrm{C}-\mathrm{C}$ and $\mathrm{C}-\mathrm{N}$ stretching. The bands corresponding to the deformation type of the vibrations of $\mathrm{NH}_{3}$ groups appear in the $1700-1500 \mathrm{~cm}^{-1}$ region. All peaks located in the frequency range of $400-1000 \mathrm{~cm}^{-1}$ are attributed to the $\mathrm{C}-\mathrm{H}, \mathrm{C}-\mathrm{C}$ and $\mathrm{C}-\mathrm{N}$ bending type of vibrations.

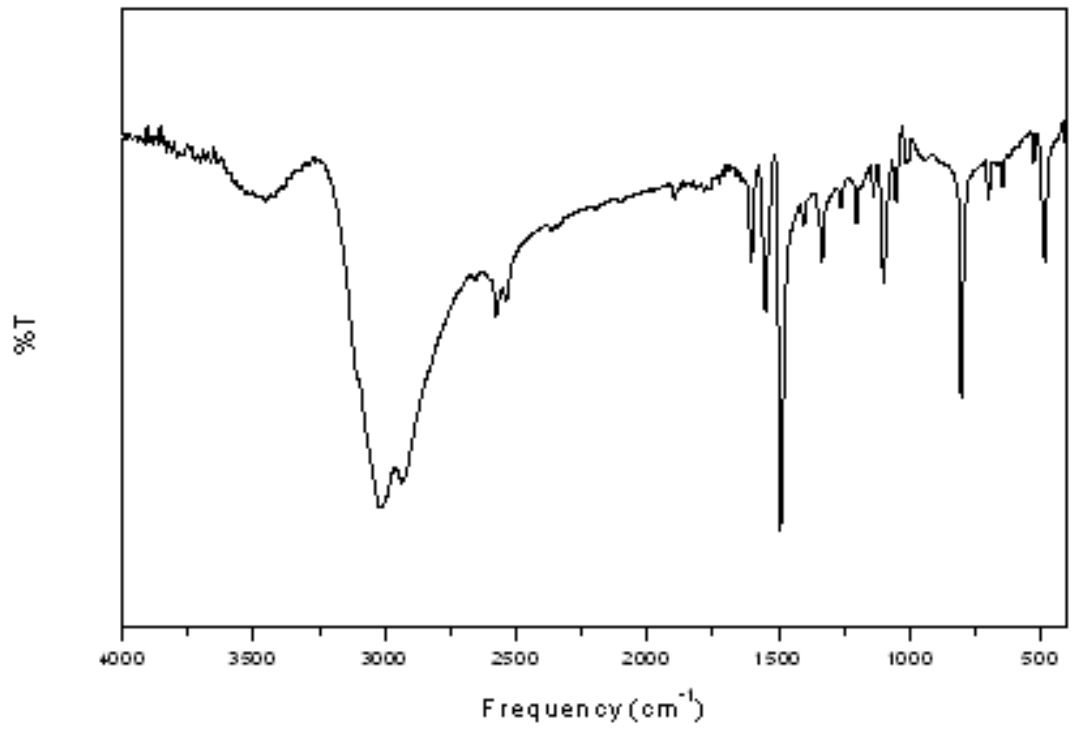

Fig 4: FT-IR spectrum of $\mathrm{C}_{12} \mathrm{H}_{14} \mathrm{~N}_{2} \mathrm{CuCl}_{4}$

\subsection{RMN spectroscopy}

The ${ }^{13} \mathrm{C}$ NMR spectrum plotted in Fig. 5 has six peaks. This result proves the presence of a half of organic cation in the asymmetric unit of the compound in agreement with the X-ray diffraction data (Fig. 6). The two peaks, located at 120.5 ppm and $126.5 \mathrm{ppm}$, are assigned to C3 and C4 carbons. The two peaks located at 132.0 and 135.3 ppm are attributed to the $\mathrm{C} 2$ and C5carbon atoms. While the peak located at $137.0 \mathrm{ppm}$ is assigned to the nucleus of the $\mathrm{C} 1$ atom, the higher chemical shift located at $139.6 \mathrm{ppm}$ is attributed to the $\mathrm{C} 6$ carbon atom linked to the $\mathrm{N} 1$ nitrogen atom [19, 20]. 

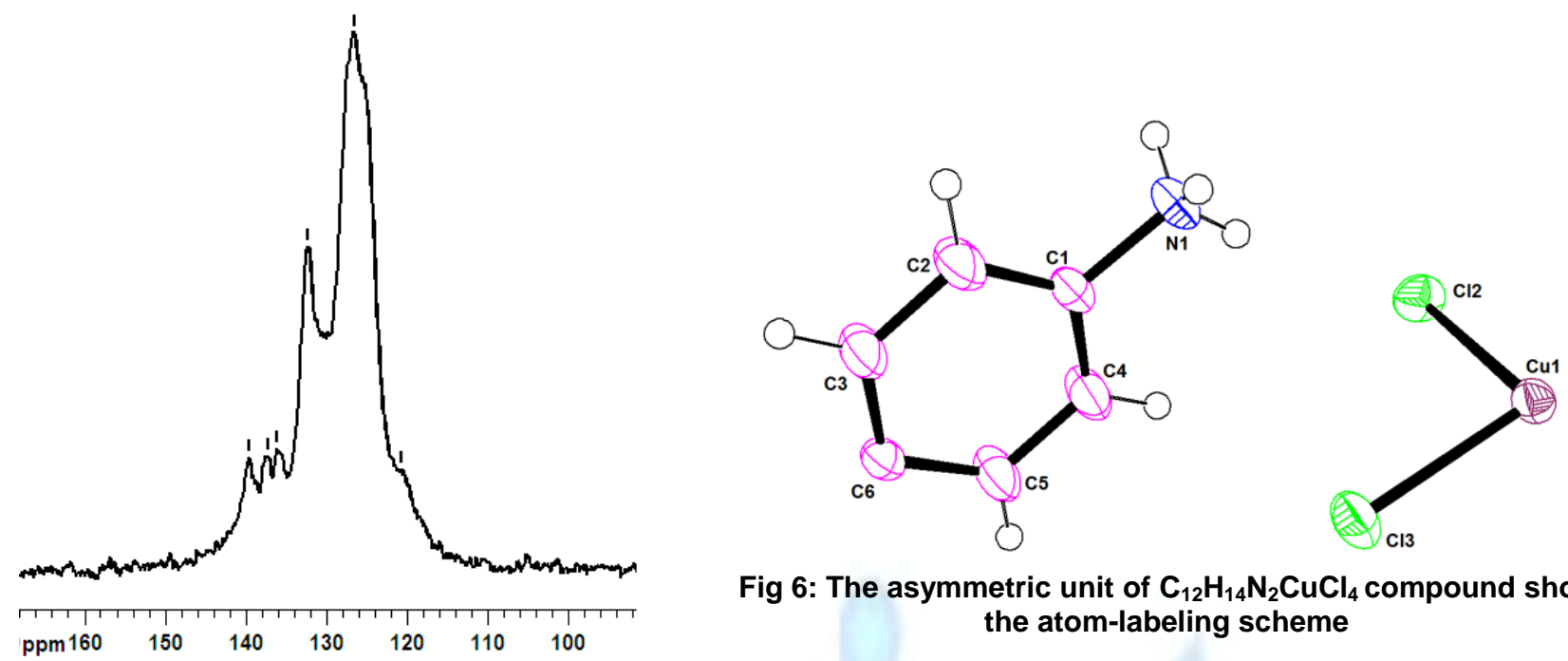

Fig 6: The asymmetric unit of $\mathrm{C}_{12} \mathrm{H}_{14} \mathrm{~N}_{2} \mathrm{CuCl}_{4}$ compound showing the atom-labeling scheme

\section{Fig 5: ${ }^{13} \mathrm{C}$ MAS-NMR spectrum of $\mathrm{C}_{12} \mathrm{H}_{14} \mathrm{~N}_{2} \mathrm{CuCl}_{4}$ compound}

\subsection{Impedance analysis}

The impedance spectra obtained at different temperatures are shown in Fig. 7 in the temperature range of 338-413 $\mathrm{K}$ and the frequency range from $209 \mathrm{~Hz}$ to $5 \mathrm{MHz}$. In the studied temperature range, Z' versus Z', arcs move to a lower value of impedance when the temperature increases. The bulk ohmic resistance values of the sample can be determined from the intercept of the semicircle, at low frequency, with the real axe ( $\left.Z^{\prime}\right)$ [21]. Such pattern tells us about the electrical process occurring within the sample and their correlation with the sample microstructure when modeled in terms of an electrical equivalent circuit [22-24]. It allows the establishment of correlations between electrochemical system parameters and impedance elements characteristics.

The equivalent circuit configuration for the impedance plane plot is well described by the parallel of a resistance Rp (bulk resistance) and constant phase elements (capacity of the fractal interface CPE). The Capacity of the fractal interface $\mathrm{CPE}$ is given by the following equation: $Z_{\mathrm{CPE}}=1 / Q_{1}(j \omega)^{\alpha}[35]$ (Fig. 8). The expressions of the real ( $\left.Z^{\prime}\right)$ and imaginary (-Z') parts of the chosen equivalent circuit are:

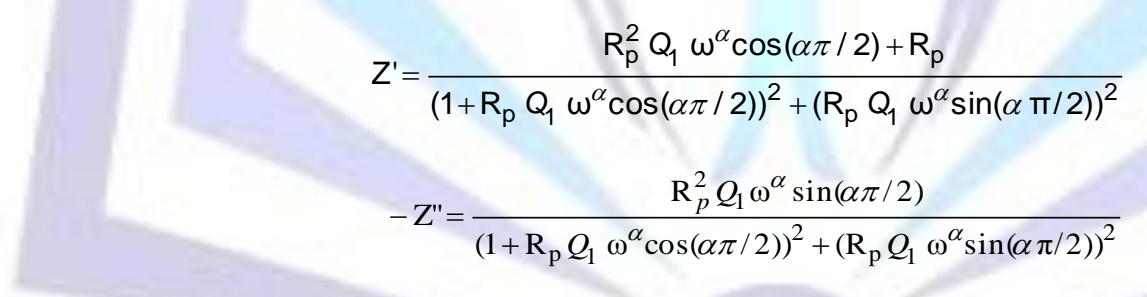

The resistance $R_{p}, 1 / Q_{1}$ and a have been simulated using a mean square method which consists in minimizing the difference between the experimental and calculated data. This parameter can be determined from the low-frequency limits of the measured impedance spectra with the following expression:

$$
\mathrm{Zp}=\lim _{\mathrm{w} \rightarrow 0}|Z|
$$

The $1 / Q_{1}$ parameter can be estimated from the frequency $\left(\omega_{\mathrm{m}}\right)$, which corresponds to the maximum $Z$ " value of the measured impedance spectra, by the following expressions: $\omega_{\mathrm{m}} \mathrm{R}_{\mathrm{p}} 1 / Q_{1}=1$. It indicates the capacitance value of the CPE element. The a parameter can be estimated by measuring the angle between the line which passes by the circle center of the impedance spectra, origin mark and real axis.

Figures 9 and 10 represent the fitting of the real and imaginary parts ( $\left.Z^{\prime} ; Z^{\prime \prime}\right)$ versus frequency at different temperatures. The curves of $Z^{\prime}$ and $Z$ ' versus frequency at several temperatures are fitted by equations (1) and (2), respectively. All fitted curves at each temperature show the good conformity of the calculated lines with the experimental data indicating that the suggested equivalent circuit describes the crystal-electrode interface reasonably well. 
In order to understand the conduction phenomena, we use Arrhenius modeling equation: $\sigma T=A \exp (-E a / k b T)$, where $E a$ is the activation energy and $\sigma$ is the conductivity. It is obtained from $Z_{0}$ by means of the relation: $\sigma=e / Z_{0} S$, where $e / S$ represents the geometrical ratio sample, $A$ is the pre-exponential factor, $k b$ is the Boltzmann constant and $T$ is the temperature. The thermal evolution of the specific conductivity (In $(\sigma T)$ versus 1000/T) of the compound is shown in Fig. 11 indicating an Arrhenius type behavior [26]. A change in the slope of the linear curve is detected around $400 \mathrm{~K}$. In this case, the activation energy (Ea) estimated from this plot is equal to 2.13 and $1.30 \mathrm{eV}$ in regions I and II, respectively. The study of the dielectric properties is an important source of valuable information about conduction processes since the origin of the dielectric losses, the electrical and dipolar relaxation time and its activation energy can be determined. Consequently, the conduction is explained by the thermally activated mechanism [27]

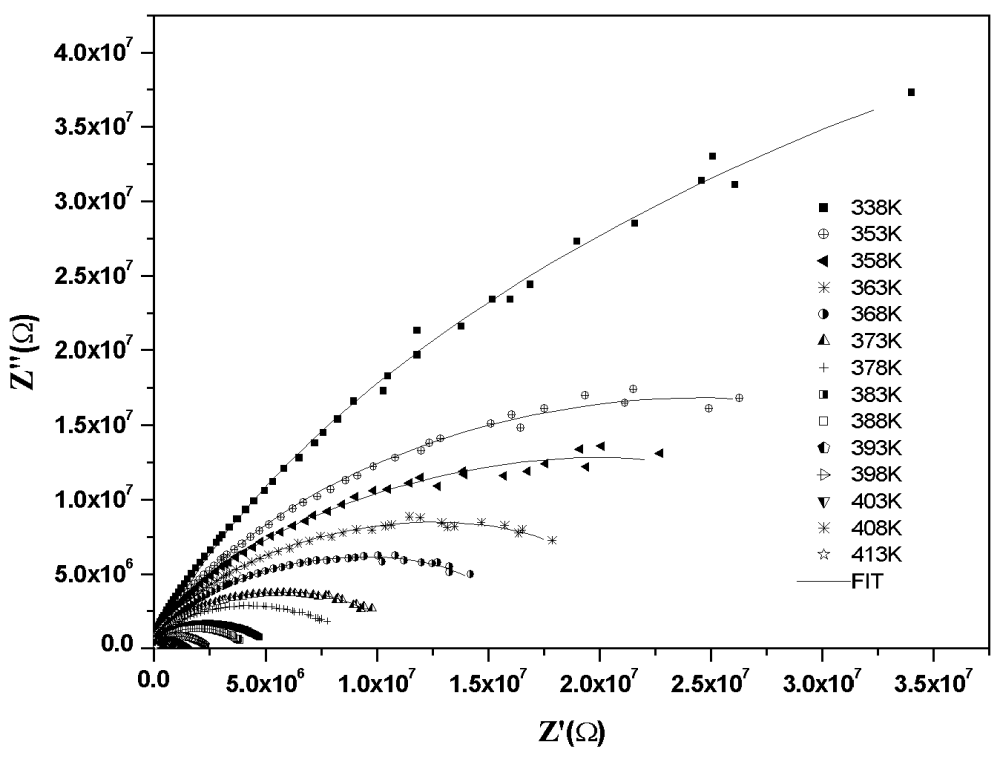

Fig 7: Complex impedance spectra of $\mathrm{C}_{12} \mathrm{H}_{14} \mathrm{~N}_{2} \mathrm{CuCl}_{4}$ at various temperatures

Fig 8: The equivalent circuits model of the $\mathrm{C}_{12} \mathrm{H}_{14} \mathrm{~N}_{2} \mathrm{CuCl}_{4}$ compound 


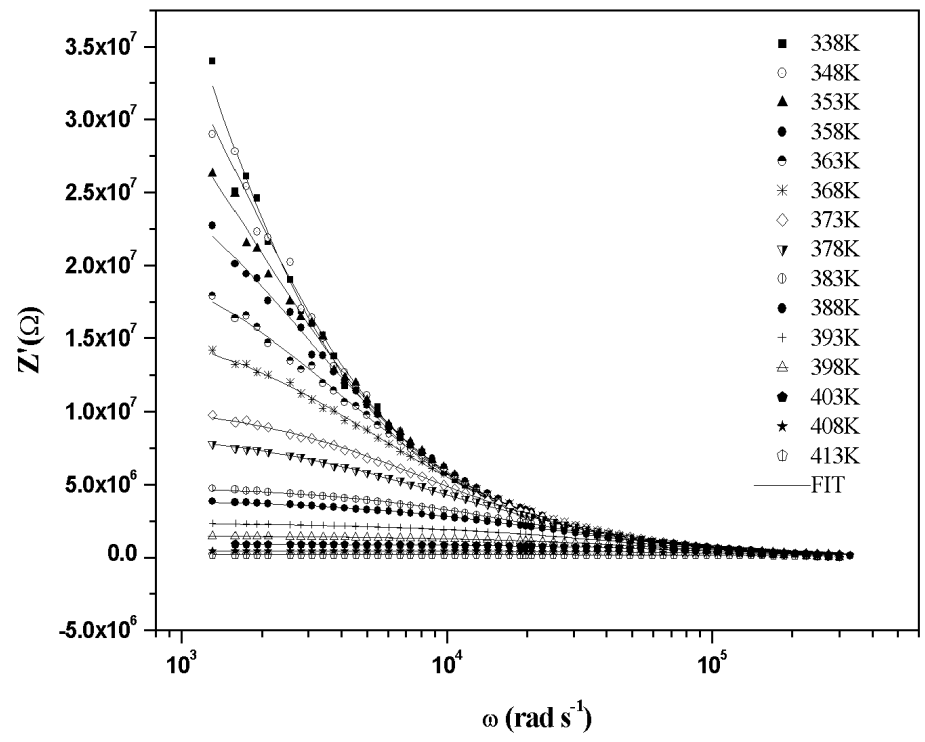

Fig 9: Variation of Z' with angular frequency at various temperatures

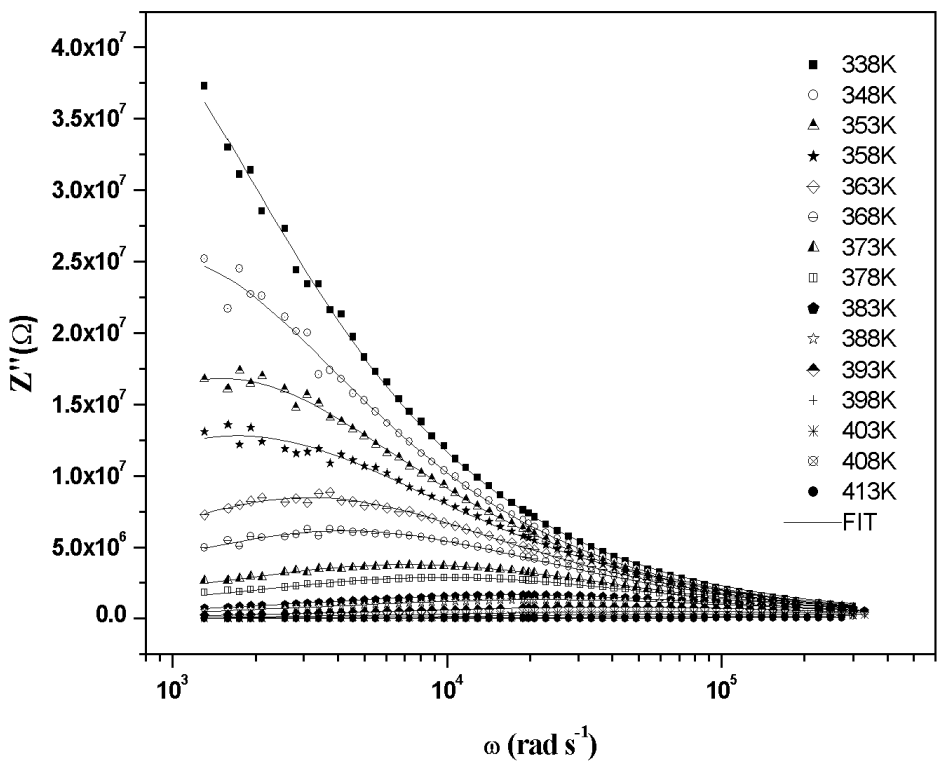

Fig 10: Variation of Z" with angular frequency at various temperatures 


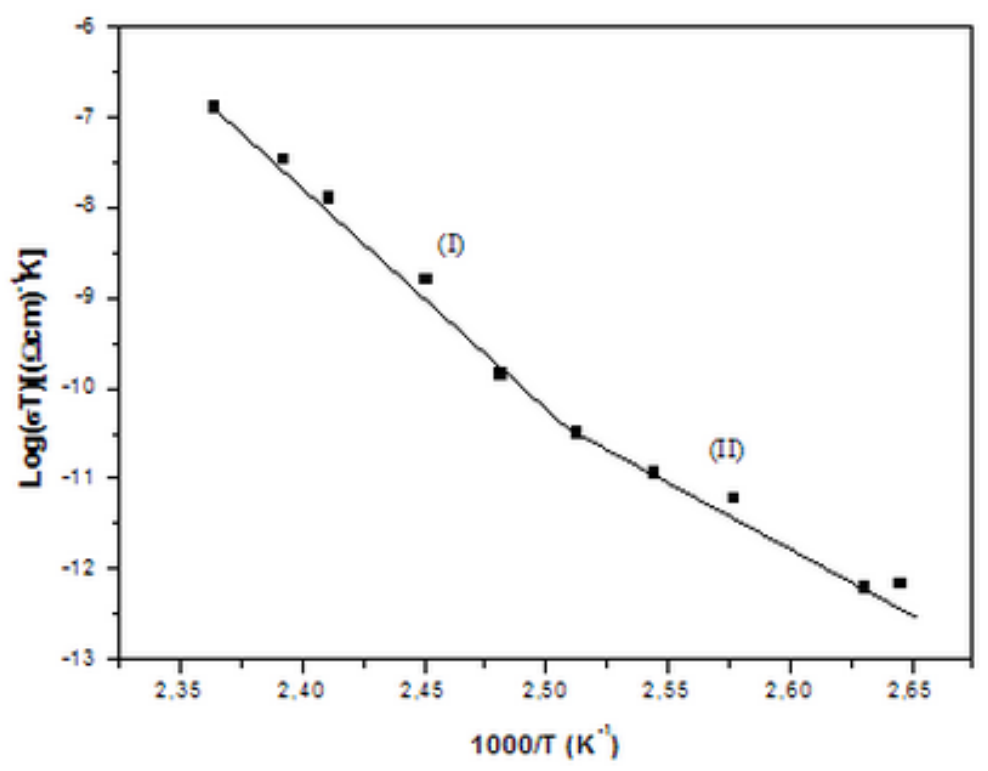

Fig 11: Temperature dependence of $\mathrm{Ln}(\sigma \mathrm{T})$ versus reciprocal temperature for the $\mathrm{C}_{12} \mathrm{H}_{14} \mathrm{~N}_{2} \mathrm{CuCl}_{4}$

\subsection{Modulus analysis}

The complex modulus formalism has been used in the analysis of the electrical properties because it gives the main response of the bulk of the polycrystalline and is particularly suitable to extract phenomena such as electrode polarization and conductivity relaxation times. The complex electric modulus can be represented by the following equations [28-31]:

$$
\begin{aligned}
& M^{*}=1 / \varepsilon^{*}=M^{\prime}+i M^{\prime \prime} \\
& M^{*}=M_{\infty}\left[1-\int_{0}^{\infty} e^{-j w t}\left(-\frac{d \varphi(t)}{d t}\right) d t\right]
\end{aligned}
$$

$M{ }_{\infty}^{\prime \prime}=1 / \varepsilon_{\infty}$ is the inverse of the high frequency dielectric constant $\varepsilon$ and the stretched exponential function is defined by the empirical Kohlrausch-Williams-Watts (K.W.W.) function [32]:

$$
\varphi(t)=\exp \left(-\left(\frac{t}{\tau_{K W W}}\right)^{\beta}\right)
$$

where the $\beta(0<\beta<1)$ parameter describes the non-exponential character of the relaxation function, and the $\mathrm{T} K w w$ is the KWW relaxation time.

\section{$\beta$ is given by:}

$\beta_{\mathrm{KWW}}=(\alpha y)^{1 / 1.23}$

Best fits for M" at different temperatures of the polycrystalline is shown in Fig. 12. M" reaches a constant value $\mathrm{M}_{\infty}\left(\mathrm{M}_{\infty}\right.$ $\left.=1 / \varepsilon_{\infty}\right)$ at high frequencies for all temperatures and this is due to the relaxation processes, which are spread over a range of frequencies [33]. The peaks in the M" plots shift toward higher frequencies and their height increases with the increase in temperature. This reveals that when the frequency is high, the temperature for which the measuring frequency is equal to $\mathrm{fp}$ is also high, while the peaks are broader and asymmetric on both sides of the maxima than predicted by ideal Debye behavior. From this graph, there are two areas in the first of which the curves are very close, while in the second, the curves are far apart. This confirms the existence of two areas of conduction. These results are consistent with those obtained from the conductivity.

The asymmetric M" plot is suggestive of the stretched exponential character of the relaxation times of the material. The stretched exponential function is defined by the empirical Kohlrausch-Williams-Watts (KWW) function Eq. (5). The $\beta$ value was determined from equation (6).

In the present case, the $\beta$ values are temperature dependent (Fig. 13). We can say that the interactions between the load carriers vary with the temperature. 


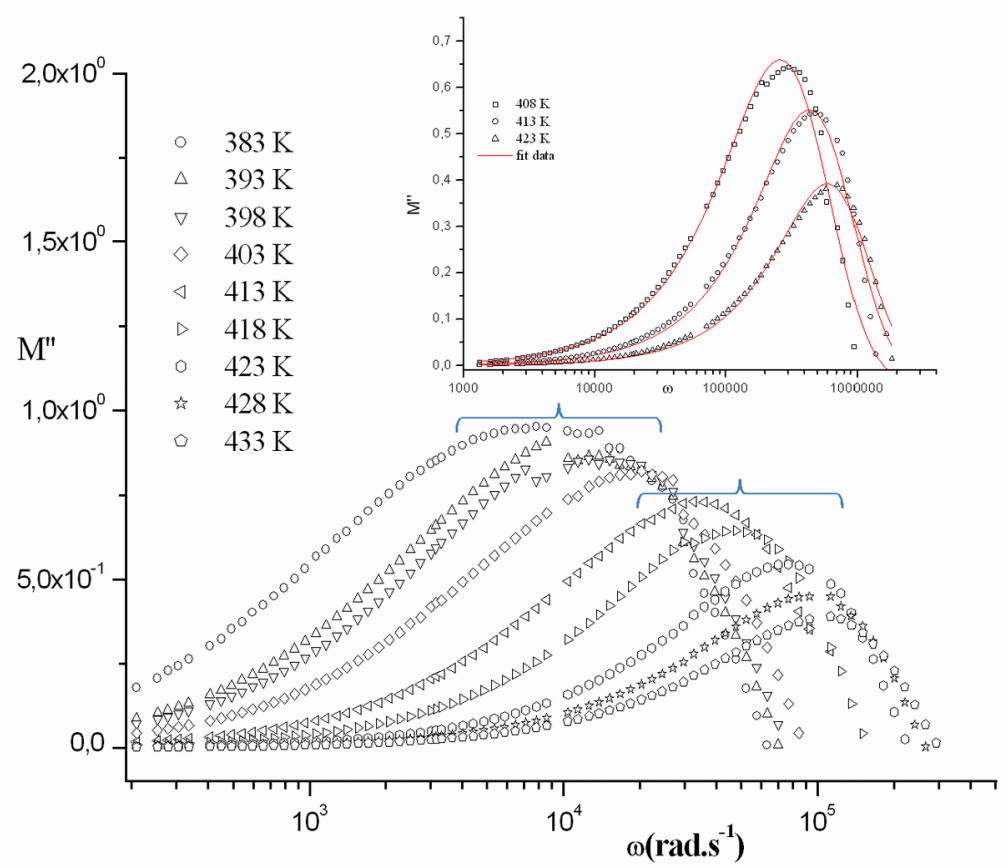

Fig 12: Frequency dependencies of $M$ " at different temperatures. Solid curves are the best fits to the modulus formalism

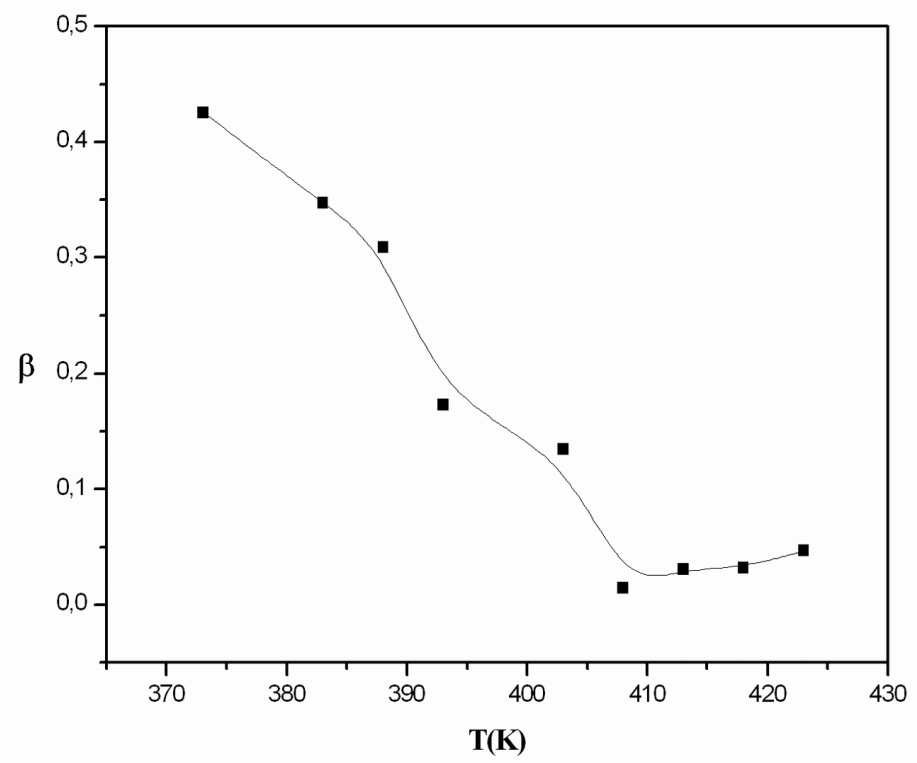

Fig 13: The values of $\beta$ as a function of temperatures

\subsection{Conductivity analysis}

The AC conductivity is generally expressed as [34]:

$$
\begin{aligned}
\sigma_{\text {Total }} & =\sigma_{d c+} \sigma_{a c} \\
& =\sigma_{0+} A \omega^{s}
\end{aligned}
$$

where $\left(\sigma_{d c}=\sigma_{0}\right)$ is the frequency-independent component, $\mathrm{A}$ is a temperature-dependent constant, $\mathrm{s}$ is the frequency exponent and $\left(\sigma_{a c}=A \omega^{s}\right)$ represents the dissipative contribution to the total conductivity, which depends both on the temperature and composition of the single crystal [35-37]. Equation (7) is referred to as the universal dynamic pattern of 
ac electrical behavior of conducting solids as proposed by Jonscher [38]. Equation 7 was used to fit the AC conductivity data. In the fitting procedure, $A$ and $s$ values have been varied simultaneously to get the best fits observed in Fig. 14 Many manifestations of the hopping models and experiments to give the value of $s$ in the range of $0.6-1$ have been given in Refs. [39, 40]. The transport mechanism is explained by the thermally activated hopping process between two sites separated by an energy barrier. Recently, the frequency dependence of electrical conductivity for the ionic single crystal has been reported [41,42]. The Jonscher's universality of AC conductivity is not limited to the case of glasses but extends to cover the ionic single crystal. The $s$ greater than 1 is excluded out in the theory, but it has been found in the experimental analysis of the crystals of $\mathrm{K}_{2} \mathrm{SO}_{4}$ [42], $\mathrm{Rb}_{3} \mathrm{H}\left(\mathrm{SO}_{4}\right)_{2}$ [43] and $\mathrm{Rb}_{3} \mathrm{H}\left(\mathrm{SeO}_{4}\right)_{2}$ [43]. In our case, the values of $\mathrm{s}$, with temperatures, vary between 0.92 and 0.94 . The exponent $\mathrm{s}$ increases with the increase in temperature. Also, studies investigated by Ganguli et al. [44] exhibit similar trend for $s$ as function of temperature. So far, no full explanation of this behavior has been found. Probably, this result is due to the interaction relative to the mobility of ions.

\subsection{Dielectric studies}

The study of the dielectric properties is an important source for valuable information about conduction processes [27]. Fig. 15 shows the frequency dependence of the dielectric constant $\varepsilon "(\omega)$ at fixed temperatures.

The measured impedance is used to calculate the imaginary $\left(\varepsilon^{\prime \prime}\right)$ parts of the complex dielectric permittivity as [45] Eq. (8):

$$
\varepsilon^{\prime \prime}(\omega)=\frac{\left(\varepsilon_{s}-\varepsilon_{\infty}\right)\left(\frac{\omega}{\omega_{1}}\right)^{1-\alpha} \sin \left(\frac{(1-\alpha) \pi}{2}\right)}{1+2\left(\frac{\omega}{\omega_{1}}\right)^{1-\alpha} \cos \left(\frac{(1-\alpha) \pi}{2}\right)+\left(\frac{\omega}{\omega_{1}}\right)^{2(1-\alpha)}}+\frac{\sigma_{0}}{\varepsilon_{0} \omega}
$$

where the parameter $\alpha$ represents the tilting angle $(\alpha \pi / 2)$ of the circular arc from the real axis in the complex permittivity plane, $\omega$ is the frequency, $\sigma_{0}$ the specific conductivity and $\varepsilon_{0}$ the dielectric permittivity of vacuum [46]. As the temperature increases, the dielectric constants at low frequency show a dispersive behavior [26]. Actually in the low frequency region of the $\varepsilon$ " spectrum, a clear tail connected to the conductivity was observed. Best fits using the function (8) give a suitable fitting of the curves resulting from the experimental data.

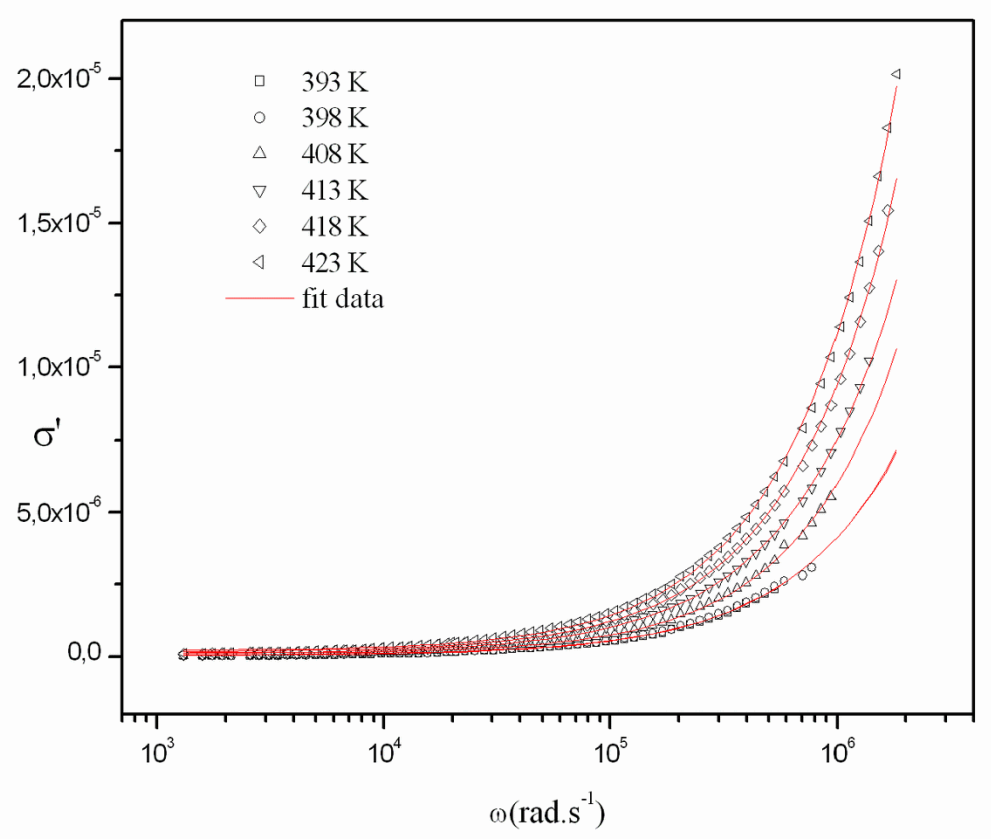

Fig 14: Frequency dependencies of the real part of Ac complex conductivity at several temperatures 


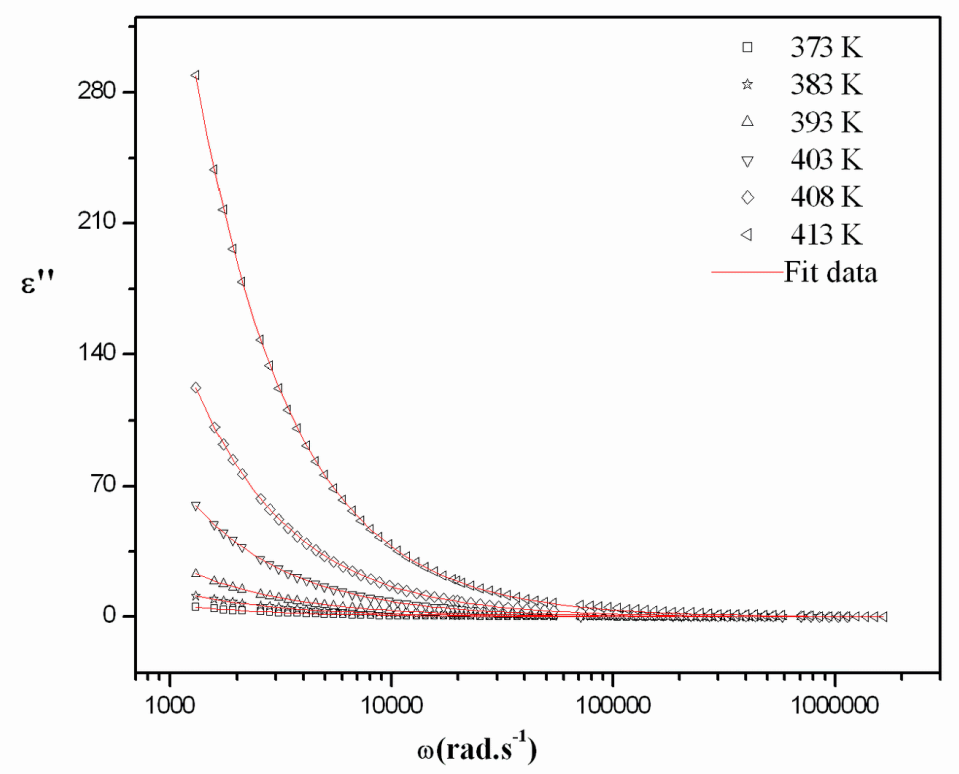

Fig 15: Frequency dependencies of the imaginary part of permittivity at several temperatures

\section{CONCLUSION}

The compound, $\mathrm{C}_{12} \mathrm{H}_{14} \mathrm{~N}_{2} \mathrm{CuCl}_{4}$, was synthesized by slow evaporation at room temperature. DSC study indicates the presence of a phase transition at $126{ }^{\circ} \mathrm{C}$. The analysis of the frequency dispersion of the real and imaginary components of the complex impedance allowed the determination of an equivalent electrical circuit for an electrochemical cell with $\mathrm{C}_{12} \mathrm{H}_{14} \mathrm{~N}_{2} \mathrm{CuCl}_{4}$. Then the $A C$ conductivity and electric behavior of $\mathrm{C}_{12} \mathrm{H}_{14} \mathrm{~N}_{2} \mathrm{CuCl}_{4}$ was studied as a function of temperature and frequency. Besides, the frequency-dependent conductivity of the material at different temperatures was analyzed using the Jonscher's power law; and, the temperature-independent frequency exponent term was evaluated. The analysis of the temperature variation of the $M$ ' peak indicates that the observed relaxation process is thermally activated. The AC conductivity is described by Jonscher's behaviour.

\section{REFERENCES}

[1] Yan, B.; Xu, Y.; N.K. Goh, L.S. Chia, Inorg. Chem. Commun. 3, (2000) 37

[2] G. Ferey, Chem. Mater. 13, 3084 (2001)

[3] T. Berrocal, J.L. Mesa, J.L. Pizarro, L. Lezama, B. Bazan, M.I. Arriortua, T. Rojo, J.Solid State Chem. 181, 884 (2008)

[4] R.D. Willett, C.J. Gomez-Garcıa, B. Twamley, Polyhedron 24, 2293 (2005)

[5] A. Jarboui, B. Louati, F. Hlel, Kamel Guidara, J. Alloys Compd. 503, 340 (2010)

[6] Z.L. Xiao, H.Z. Chen, M. Wang, B.Z. Tang, J. Funct. Mater. 8, 1217 (2005)

[7] J. Diaz-Hernández, G. Aguirre-Zamalloa, A. López-Echarri, I. Ruiz-Larrea, T. Breczewski, M. J. Tello, J. Phys. Condens.Matter 9, 3399 (1997)

[8] A. Ben. Rhaiem, N. Zouari, K. Guidara, M. Gargouri, A. Daoud, J. Alloys. Compd. 387,1 (2005)

[9] M. Pollak, T. H. Geballe, J. Phys. Rev. 122, 1742 (1961)

[10] S. R. Elliott, N. F. Mott, J. Adv. Phys. 18, 41(1969)

[11] S. Sen, R. N. P. Chaudhary, Mater. Chem. Phys. 87, 256 (2004)

[12] J. Suchanicz, Mater. Sci. Eng. B. 55, 114 (1998)

[13] M.Belhouchet, W. Wamani, T. Mhiri, IOP Conf. Series: Materials Science and Engineering 13,12039 (2010)

[14] H. A. Jahn, E. Teller, Proc. R. Soc. Lond. Series A - Math. Phys. Sci.161, 220 (1937)

[15] D. B. Mitzi, Chem. Mater 8, 791, (1996)

[16] T. Yoshinari, T. Nanba, S. Shinamuki, M. Fujisawa, R. Aoyagi, J. Phys. Soc. Jpn. 61, 2224 (1992) 
[17] C. Topacli, A. Topacli, Mol.Struct.9, 658(2007)

[18] E. Akalin, S. Akyüz, Mol. Struct.571, 651 (2003)

[19] A. Mahroug, M. Belhouchet, A.H. Ribaud, T. Mhiri, Phosphorus, Sulfur Silicon Relat. Elem.186, 2332 (2011)

[20] A. Mahroug, M. Belhouchet, T. Mhiri, Phosphorus, Sulfur Silicon Relat. Elem. 187, 1482 (2012)

[21] K. S. Rao, D. M. Prasad, P. M. Krishna, B. Tilak, K. Ch. Varadarajulu, Mater. Sci. Eng. B. 133, 141(2006)

[22] A. Ben. Rhaiem, K. Guidara, M. Gargouri, A. Daoud, J. Alloys. Compd. 392, 68 (2005)

[23] D.K. Parathan, B. K. Samantry, R.N.P. Chauthaev, A.K. Thakur, Mater. Sci. Eng. B 116, 431 (2005)

[24] M. Nadeem, M.J. Akthar, A.Y. Khan, Solid State Commun. 134, 431 (2005)

[25] P. Muralidharan, M. Venkateswarlu, N. Satyanarayana, J. Non-Cryst. Solids 351, 538 (2005)

[26] K.S. Rao, P.M. Krishna, D.M. Prasad, J.H. Lee, J.S. Kim ,J. Alloys Compd. 464, 497 (2008)

[27] R. Ayouchi, D. Leien, F. Martin, M. Gabas, E. Dalchiele, J. R. Ramos-Barrodo, Thin Solid Films 68, 426 (2003)

[28] P.B. Macedo, C. T .Mognihan, R. Bose, Phys. Chem. Glasses 13, 171 (1972)

[29] M. Ganguli, M. Harish Bhat, K. Rao, J. Phys. Chem. Glasses 40, 297(1999)

[30] S. Lanfredi, P. S. Saia, R. Lebullenger, A. C. Hernandes, Solid State Ionics 146, 329 (2002)

[31] S. Ghosh, A. Ghosh, Solid State lonics 149,67 (2002)

[32] G.Williams, D. C. Watts, Trans. Faraday Soc.66, 80 (1970)

[33] F. S. Howell, Bose, P. B. Macedo,C. T. Moynihan, J. Phys. Chem. 78, 639 (1974)

[34] A. Mansingh, V. K Dhawan, J. Phys. C. Solid State Phys. 16, 1675 (1983)

[35] H. El Mkami, B.Deroide, R. Backov, J .Vzanchetta ,J.Phys. Chem. Solids 61, 819 (2000)

[36] N. F. Mott, E.A .Davis, Electronic Processes in Non-crystalline Materials, seconded. Clarendon, Oxford 225 (1979)

[37] S.R. Elliott, Adv Phys.36, 135 (1987)

[38] A.K. Jonscher, Nature 267, 673 (1977)

[39] J.C. Dyre, T.B. Schroder, Rev. Mod. Phys. 72, 873 (2000)

[40] J.C. Dyre, J. Appl. Phys. 64, 2456 (1988)

[41] R.H. Chen, T.M. Chen, C.S. Shern, J. Phys. Chem. Solids 61, 1399 (2002)

[42] R.H. Chen, C.S. Shern, T. Fukami, J. Phys. Chem. Solids 63, 203 (2002)

[43] A.L. Chang, Master Thesis, National Taiwan Normal University, 1999

[44] M. Ganguli, M.H. Bhat, K.J. Rao, Mater. Res. Bull. 34, 1757 (1999)

[45] J. Suchanicz, Mater. Sci. Eng. B55, 114 (1998)

[46] K. S. Cole, R. H. Cole, J. Chem. Phys. 9, 341 (1941) 